Lic. en Trabajo Social por la UNR. Master en Servicio Social por la Escuela de Servicio Social de la Universidad Federal de Río de Janeiro. Estudiante de Doctorado de la misma institución, con apoyo financiero de la CNPq. Miembro del Grupo de Estudios de América Latina (GEAL) y del Núcleo de Estudio y Pesquisas Marxistas (NEPEM).

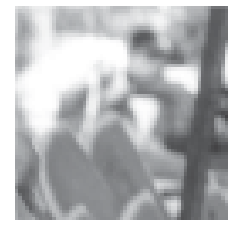

\title{
Hacia la Construcción de un Trabajo Social Crítico Latinomericano: Algunos Elementos para su Problematización
}

RESUMEN El siguiente trabajo caracteriza primeramente, el significado y los fundamentos socio-históricos del TS, analizando diversas determinaciones de la práctica profesional-importantes para la reflexión en torno de sus límites y posibilidades-, dando especial interés a algunas de sus particularidades que nos llevan a discutir en torno al problema de la «especificidad», a la dimensión política del ejercicio profesional, su relación con la militancia, etc. Posteriormente, nos centramos en algunos ejes analíticos que nos posibiliten pensar en el proyecto ético-político como posibilidad de incidir críticamente en la configuración de una dirección social alternativa de la práctica profesional. Este trabajo pretende presentar apenas algunas coordenadas teórico-conceptuales generales para el debate que, sin pretensiones de agotarlo, consideramos fundamentales.

PALABRAS CLAVES Proyecto Ético-Político - Trabajo Social - Luchas Sociales - Latinoamérica

\section{Introducción}

El siguiente trabajo consta de dos partes fundamentales. La primera, busca comprender el significado socio-histórico del Trabajo Social (TS) como profesión situada en la división social del trabajo, participando en la reproducción de las relaciones sociales. A partir de este marco general de interpretación intentaremos desarrollar el debate "especialización vs. especificidad", dando especial destaque a algunas particularidades que constituyen el ejercicio profesional. En esta misma línea, buscaremos resaltar, entre otras determinaciones históricas de la práctica profesional, el carácter político del TS, abordando temas tales como ejercicio profesional y militancia. 


\section{Katia I. Marro}

Ya en la segunda parte, intentaremos desarrollar algunos interrogantes que nos ayuden a pensar el Proyecto Ético-Político Profesional (PEPP) y tentativas de construcción de un Trabajo Social crítico: ¿qué significa?; ¿cuál es su importancia?; ¿cuáles son sus desafíos?, entre otros.

De esta manera aproximativa y sin pretender agotar el debate en su complejidad, abordamos algunas cuestiones que nos parecen centrales a la hora de comprender la significación histórica y los desafíos del PEPP del TS en los días actuales.

\section{Algunas notas sobre el significado socio-histórico del Trabajo Social}

Uno de los saldos de mayor importancia para el Trabajo Social en su interlocución con la teoría social crítica, es la comprensión de su significado sociohistórico en el marco de la producción y reproducción de las relaciones sociales. Veremos entonces que, el análisis crítico y riguroso de su significado histórico -el Trabajo Social en el cuadro de las relaciones sociales capitalistas, en estrecha relación con la sistemática intervención del Estado frente al conflicto social y las desigualdades sociales en la fase del monopolio-, es una condición fundamental para la comprensión de las posibilidades y límites de nuestra profesión en la sociedad contemporánea.

De este modo, comenzaremos por situar al Trabajo Social en la división sociotécnica del trabajo y a partir de allí, reflexionar en torno de otros determinantes históricos de nuestra profesión, fundamentales para la comprensión de su significado socio-histórico: su participación en el proceso de reproducción de las relaciones sociales; su carácter de profesión asalariada a partir de una especialización del trabajo colectivo; su ubicación en el ámbito de las relaciones entre las clases y de éstas con el Estado en el contexto monopolista; dimensiones objetivas y subjetivas de la práctica profesional; su naturaleza polarizada y contradictoria; su carácter político; etc. Tan lejos de representar este ejercicio de reflexión crítica una "actitud detractora" o "fatalista" ${ }^{1}$ acerca de la naturaleza socio-histórica del TS, se constituye como un esfuerzo fundamental y necesario para la comprensión de sus particularidades, en la perspectiva del compromiso con un proyecto societario crítico al vigente. Porque es la existencia y comprensión del carácter contradictorio de la práctica profesional lo que posibilita que el Trabajador Social se coloque al servicio de un proyecto de clase alternativo a aquel para el cual es Ilamado a intervenir -permitiendo una rigurosa comprensión teórica de las implicancias de su práctica profesional, y un mayor control y dirección de la misma, en el marco de los límites establecidos por el proceso social (lamamoto, 1992: 110).

\subsection{Trabajo Social en la división socio-técnica del trabajo: "cues- tión social" y reproducción de las relaciones sociales}

La perspectiva histórico-crítica nos ha mostrado que el TS no es una evolución de la caridad y la filantropía, antes que esto, se constituye como profesión respondiendo a necesidades sociales derivadas de la práctica de las clases sociales en el

${ }^{1}$ Perspectiva defendida en el libro organizado por DI CARLO, E. La profesión de Trabajo Social. Naturaleza, significado social y formas de acción profesional. Tomo 1. Mar del Plata, UndMP, 2004. 
proceso de producción y reproducción de sus medios de vida y de trabajo, de forma socialmente determinada (lamamoto, 1997: XXV). De esta forma, el TS surge como profesión en tanto especialización del trabajo colectivo, en la división socio-técnica del trabajo, como uno de los agentes responsables por la ejecución de las políticas sociales estatales orientadas para la atención de las secuelas de la llamada "cuestión social", en el momento histórico en que el Estado comienza a dar respuestas sistemáticas frente a ésta, esto es, la internaliza en su funcionalidad -con la consolidación del capitalismo monopolista ${ }^{2}$.

El carácter de instrumento de racionalización y administración de los conflictos con que surge el TS -como un mecanismo utilizado por las clases dominantes para el ejercicio de su dominación-, aparece sintetizado en estas palabras:

"Así, el Servicio Social nace como parte de una estrategia de clase, dentro del proyecto burgués, de 'reformas dentro del orden', articulado por las fuerzas sociales que representan el gran capital [...], buscando la integración de la clase trabajadora, teniendo en cuenta las posibilidades económico-sociales puestas por el monopolio en el momento en que el Estado asume para sí el tratamiento de la cuestión social"3.

De esta forma, el TS se institucionaliza y legitima profesionalmente como uno de los recursos movilizado por el Estado (en su intervención progresiva para la regulación del conflicto social, en el período de consolidación de la fase imperialista del capitalismo) en el enfrentamiento de las secuelas sociales de la contradicción capital/trabajo ${ }^{4}$, cuando su intensidad y extensión adquieren una expresión política significativa en el cotidiano de la vida social. Por ello, es necesario reconocer que:

"Fueron las luchas sociales las que rompieron el dominio privado en las relaciones entre capital y trabajo, extrapolando la cuestión social para la esfera pública, exigiendo la interferencia del Estado para el reconocimiento y la legalización de derechos y deberes de los sujetos sociales involucrados"5.

La "cuestión social" -indisociable de las relaciones sociales capitalistas en el marco de la expansión monopolista y de su enfrentamiento por parte del Estado-está en la base de la profesionalización del TS: una profesión que, en su carácter preponderante técnico-interventivo ${ }^{6}$, cumple su función en el proceso de reproducción de las relaciones sociales capitalistas, y consecuentemente, en el proceso de reproduc-

\footnotetext{
2 Esta afirmación no desconsidera las particularidades históricas con que el proceso de consolidación del capitalismo monopolista en diversos países, se materializó Antes que eso, busca comprender dicho proceso en la totalidad en que se enmarca.

${ }^{3}$ Gerra en: BORGIANNI, E.; GUERRA, Y.; MONTAÑO, C. Servicio Social Crítico. Hacia la construcción del nuevo proyecto ético-político profesional. São Paulo, Cortez, 2003, p. 188.

${ }^{4}$ De esta forma, la llamada «cuestión social» está esencialmente determinada por la relación capital-trabajo, siendo la explotación su determinación molecular, se encuentra mediada por componentes históricos, políticos, culturales. Ella se constituye como el conjunto de problemas económicos, sociales, políticos, culturales e ideológicos que delimitan la emergencia de la clase obrera como sujeto socio-político en la sociedad burguesa (Netto en: Borgianni; Guerra; Montaño, 2003: 154).

${ }^{5}$ IAMAMOTO, M. «A questão social no capitalismo» en: Revista Praia Vermelha ${ }^{\circ}{ }^{\circ}$. Rio de Janeiro, UFRJ/ PPGESS, 2003, p. 66. Traducción K. Marro.

${ }^{6}$ Por ello, para lamamoto (1997: 138), la demanda del TS por las clases poseedoras, puede ser comprendida como una de las «tecnologías» puestas al servicio de la reproducción de la fuerza de trabajo, del control social y de la difusión de la ideología dominante entre las clases subalternas.
} 


\section{Katia I. Marro}

ción de las clases sociales fundamentales. La actuación del TS supone la intervención en la reproducción de la fuerza de trabajo, al mismo tiempo que implica la reproducción del control social y de la ideología dominante, sin por ello dejar de apuntar su participación en la reproducción de las contradicciones sociales -dimensiones ineliminables de un mismo quehacer profesional.

El significado del Trabajo Social en la división socio-técnica del trabajo colectivo se constituye a partir de la demanda por la prestación de servicios sociales y desarrollando una actividad educativa (o político-ideológica), interviniendo estas en la reproducción social (material e ideológica) de la vida de las clases subalternas. Por estas razones, podemos afirmar que la práctica profesional se encuentra polarizada por intereses de clase, siendo esta una característica constitutiva e ineliminable de la misma: reproduce intereses contrapuestos y su antagonismo; participa tanto de los mecanismos de explotación y dominación, como también, al mismo tiempo, da respuesta a las necesidades legítimas de sobre-vivencia de las clases subalternas. Esta perspectiva también nos permite entender el carácter contradictorio del TS, derivado del propio carácter contradictorio de las relaciones sociales, en cuanto relaciones de clases que configuran la sociedad capitalista. De esta manera, el TS en el ámbito de la totalidad social se constituye como:

"[...] actividad auxiliar y subsidiaria en la reproducción de la fuerza de trabajo vía la prestación de servicios sociales, vistos como salario indirecto -, del control social y de la ideología, parte del proceso de disputa por la hegemonía, recreando necesariamente las contradicciones entre las clases, sus desigualdades y las luchas entre los sujetos sociales en esa sociedad"7.

Si el TS surge como una "tecnología" para dar respuesta a los intereses del capital, esta dimensión, siendo predominante, no es monolítica ni exclusiva en la práctica profesional, desde el momento en que, por su propio carácter contradictorio que la dota de autonomía relativa -siendo una condición esencial la comprensión crítica de dicho movimiento contradictorio- es posible para el Trabajador Social trabajar también al servicio de las necesidades emancipatorias de las clases subalternas. De esto se desprende que, la comprensión del significado social del TS supone una doble dimensión (elementos inseparables e interdependientes) constituida por las determinaciones históricas objetivas de la práctica profesional -su modo de inserción en las relaciones sociales como una especialización del trabajo colectivo-y el modo de pensar/actuar presente en las respuestas del colectivo profesional ante las demandas sociales -realidad vivida y representada en la conciencia de los profesionales. Ni unilateralismos ni dualidades -presentes en las dos "caras de la moneda" del fatalismo y el mesianismo, propias de nuestra tradición (Imamoto, 1997)-, sino la comprensión crítica y rigurosa de las posibilidades históricas (subjetivas y objetivas) presentes en nuestra práctica profesional. Sintetizando:

"[...] si la historia abre límites y posibilidades para las acciones de los sujetos, estos límites y posibilidades sólo se transforman en alternativas profesionales, cuando son apropiados por el colectivo profesional y traducidos en propuestas por éste

${ }^{7}$ IAMAMOTO, M. «A questão social no capitalismo». Op. Cit., p. 79. Traducción K. Marro. 
construidas en la esfera de la investigación, de la formación y de la práctica del Servicio Social"s.

De esta forma, tanto las características del quehacer profesional tradicional (en lo que respecta a su carácter técnico y manipulatorio; repetitivo; burocrático), como sus fuentes de legitimidad social, siendo mediadas por la comprensión y apropiación rigurosa de sus dimensiones objetivas y subjetivas, pueden resignificarse críticamente en una dirección social establecida y disputada por un proyecto profesional colectivo anclado con las luchas sociales de nuestra sociedad. Volveremos más adelante sobre este asunto.

\subsection{EI Trabajo Social como especialización del trabajo colectivo: de- batiendo con la tan mentada "especificidad"}

Ubicar la comprensión del TS en el cuadro de las relaciones sociales capitalistas, nos ha mostrado las limitaciones de las perspectivas que han tendido a entenderlo de forma endógena, a partir de una supuesta "realidad interna" diversa y, en el mejor de los casos, condicionada, por una realidad "externa" a la profesión. La perspectiva histórico-crítica nos posibilitó entender el significado del TS a partir de su inserción en la división socio-técnica del trabajo sin que ello implique un descuido de las particularidades que configuran nuestra profesión. Veamos más de cerca estas cuestiones.

EI TS se sitúa en la división social y técnica del trabajo, como un tipo de especialización del trabajo colectivo, para dar respuesta a las diversas refracciones de la "cuestión social": se constituye como un trabajo especializado, que participa, fundamentalmente, en los procesos que tienen como objetivo la producción y reproducción social de la vida de las clases subalternas. Siendo que la profesión no se dedica preferentemente al desempeño de funciones directamente productivas, participa con otras profesiones en la tarea de implementar condiciones político-ideológicas necesarias al proceso de reproducción en su conjunto -indispensables o facilitadoras del movimiento del capital porque tornan más eficientes el trabajo productivo (lamamoto, 1997: 101)

El origen y el carácter técnico-interventivo de nuestra profesión, y su funcionalidad en la sociedad capitalista consolidada, nos muestran que no existe en ella una especificidad que la constituya como disciplina científica (o rama del conocimiento), mucho menos, una especificidad en sus procedimientos de intervención. Esta histórica -y en última instancia, inocua- polémica en la categoría profesional, presente en cierta tradición profesionalista/ cientificista, pasando por tendencias tecnocráticas y abarcando también tentativas de dar respuesta ante las "existenciales" crisis de la profesión, encuentra limitaciones en la comprensión de los trazos del significado histórico del TS que hacen de él una "tecnología" para intervenir en las refracciones y múltiples secuelas derivadas de la contradicción capital/trabajo.

Reconocer el carácter especializado (y no una supuesta especificidad) del TS, no implica desconocer las particularidades de la práctica profesional, mucho menos, su carácter de utilidad para la sociedad, emanada de las necesidades sociales legíti-

${ }^{8}$ Iamamoto en: BORGIANNI, E.; GUERRA, Y.; MONTAÑO, C. Op. Cit., p. 252. 


\section{Katia I. Marro}

mas de la práctica de las clases sociales. De la misma manera, afirmar la inexistencia de una "teoría específica" o de una "metodología propia" del TS en nada se iguala (como parecen insinuar algunas propuestas que desvirtúan el debate) con una burda postulación que renuncie a la importancia de la formación teórico-metodológica rigurosa en el ámbito de la profesión. Inclusive porque desde las particularidades del ejercicio profesional (tanto en la intervención y el saber que la misma produce, como en la investigación, pudiendo constituirse como un área de producción de conocimientos) $)^{9}$ es posible aportar y enriquecer el acervo del conocimiento crítico sobre la sociedad contemporánea y las diversas expresiones de la "cuestión social".

Por ello, lo que fundamenta la legitimidad de nuestra profesión no es el estatuto profesional o científico (sus metodologías y su instrumental técnico-operativo), sino la relación tensa y contradictoria que se da entre la existencia de contratos e instituciones que demanden el accionar profesional, y la existencia de luchas sociales que, politizando las necesidades sociales, exigen respuestas sistemáticas y progresivas.

Finalmente, a modo de síntesis, podemos mencionar diversas dimensiones que componen el TS en cuanto especialización del trabajo colectivo, inclusive para pensar algunas relaciones y diferencias entre trabajo profesional y militancia, para analizar posteriormente, los componentes que constituyen el carácter político de la práctica profesional.

En primer lugar, comprendimos que el SS se inserta en la división social del trabajo como una profesión no liberal, fundamentalmente, porque no dispone del control de las condiciones materiales, organizacionales y técnicas para el ejercicio de su trabajo. De ahí que, una de las condiciones para su realización sea la venta de la fuerza de trabajo del TS, en cuanto trabajador asalariado.

En segundo lugar, analizamos la inexistencia de una supuesta "especificidad" (como rama del conocimiento y en sus procedimientos de intervención) del TS, apuntando en cambio, algunas de sus particularidades, las que derivan tanto de las respuestas formuladas por los profesionales a las demandas de los grupos y clases sociales que configuran el mercado de trabajo del TS, como de las formas de organización del colectivo profesional, como así también de las formulaciones teóricometodológicas construidas (Yazbek en: Borgianni; Guerra; Montaño, 2003: 46). En este sentido, entendimos al TS como especialización del trabajo colectivo, en su utilidad social; legitimada socialmente porque responde institucionalmente a necesidades sociales.

Por estas razones, podemos afirmar que el TS (a diferencia de la actividad voluntaria, o militante) se afirma como profesión porque se encuentra incluido en una relación de compra-venta de su fuerza de trabajo. En otras palabras:

"El asistente social presta servicios y/o administra servicios sociales que son la base material a partir de la cual desarrolla una acción ideológica, política y educativa. La prestación de servicios por parte del asistente social, es mediada por una relación institucional, que legitima el Servicio Social y lo profesionaliza, incorporándo-

\footnotetext{
${ }^{9}$ Particularidades dadas por la inserción del TS en la división social y técnica del trabajo, como una profesión demandada para dar respuestas (a través de servicios sociales y actividades educativas) ante las múltiples refracciones de la «cuestión social»: profesional de la ayuda, de la asistencia, desarrollando una acción pedagógica, distribuyendo recursos materiales, testificando carencias, visibilizando derechos sociales, beneficios, etc. (Yazbek en: Borgianni; Guerra; Montaño, 2003: 48).
} 
lo al mercado de trabajo a través de un contrato de compra y venta de su fuerza de trabajo asalariada"10.

Ello nos permite entender que ante la inexistencia de dicha relación salarial, no hay práctica profesional -lo que no niega que en este marco se desarrollen actividades que forman parte de la consolidación de determinado proyecto profesional, como por ejemplo, actividades militantes fundamentales para la categoría profesional. Siendo que nuestra profesión no posee una especificidad y que, desde una perspectiva crítica, la particularidad de nuestra intervención consiste en la dirección diferente que podemos imprimir en la prestación de servicios, en la educación en torno a derechos sociales -buscando ampliar el margen de las contradicciones-, con la inexistencia de un vínculo institucional, esa posibilidad se disuelve.

Por ello, se hace necesario pensar el ejercicio profesional a partir de sus implicaciones en la órbita de las condiciones y relaciones de trabajo en que se inserta, destacando tanto sus características en cuanto trabajo concreto, como sus vínculos con el proceso de producción y distribución de la riqueza social, abarcando sus implicaciones en tanto trabajo abstracto (lamamoto, 2003: 81).

Trabajo voluntario / trabajo militante y trabajo profesional encuentran algunas diferencias, inclusive cuando la actividad concreta desarrollada (actividad que no posee una especificidad) sea "idéntica", porque el sentido y resultado social son distintos, desde el momento en que es la mediación de la venta de la fuerza de trabajo -la inserción en un medio institucional- constitutiva de nuestra profesión. Es importante resaltar que, no hay en esta distinción destacada un rechazo conservador a la militancia en el ámbito del TS, mucho menos, una dicotomía entre valores políticos y accionar profesional, inclusive porque es nuestra tarea prioritaria recuperar la importancia de dicha militancia en la construcción de un proyecto profesional comprometido con las luchas de los sectores populares ${ }^{11}$. Diferenciarlos es también una forma de comprender sus particularidades y resaltar la importancia propia de cada uno de ellos en estos tiempos históricos ${ }^{12}$, de ponderar la significación de la militancia dentro del TS, alejándola de cualquier viso conservador, inclusive permeando intenciones progresistas ${ }^{13}$.

\footnotetext{
${ }^{10}$ V.v.A.a. Serviço Social Crítico: problemas e perspectivas. São Paulo, Cortez, 1986, p. 59. Traducción K. Marro.

${ }^{11}$ De forma sucinta (ya que no pretendemos agotar este tema), debemos reconocer que existen diferencias entre el trabajo profesional sin remuneración que se realiza de forma temporaria para conseguir un contrato laboral en un futuro breve (muy propio de las condiciones de trabajo actuales) y el trabajo militante (en el ámbito del TS) orientado por objetivos políticos y valores éticos propios de dicho ámbito. Tampoco estamos refiriéndonos aquí al trabajo del docente universitario, en muchos casos realizado ad honorem.

${ }^{12}$ Es importante notar que, el contexto actual de desempleo y crisis social (elementos que repercuten directamente en el TS) favorece/propicia, dentro de la profesión, tendencias a la unilateralización de los elementos que configuran la legitimidad profesional. Si la perspectiva que hipertrofia la legitimidad en la demanda institucional queda presa del fatalismo, las tendencias que la reducen a la existencia de luchas sociales peca de mesianismo. Vimos con anterioridad, la importancia de comprender la relación tensa y contradictoria que existe entre ambos elementos que constituyen la legitimidad del TS, como una condición para entender el espacio donde se gestan las posibilidades y desafíos de nuestra profesión.

${ }^{13}$ Es necesario comprender, inclusive dentro de una perspectiva crítica del TS, que militancia no es «mala palabra», por el contrario, ella es constitutiva de un proyecto profesional colectivo que pretenda la construcción hegemónica de un TS anclado a luchas emancipatorias. Para ello, es preciso depurarlo de «elementos vocacionales» (cualidades personales y morales, apelo ético, religioso o político, el discurso altruista) -propios de nuestra tradición- para comprender sus particularidades y direccionarlo hacia los objetivos ético-políticos (a través del trabajo profesional y de la militancia, en sus funciones diversas) construidos colectivamente.
} 


\section{Katia I. Marro}

De esta forma, necesitamos comprender con rigurosidad las posibilidades y límites de nuestro trabajo profesional, porque ello es una condición para la orientación alternativa de nuestras prácticas profesionales.

EI TS como profesión es portador de una necesaria dimensión política que congrega en su interior perspectivas societarias distintas.

\subsection{Breve reflexión sobre la dimensión política del ejercicio profe- sional}

Nos toca ahora reflexionar en torno de la dimensión política del TS, sobresaltando algunos de sus elementos constitutivos.

Primeramente podríamos afirmar que el carácter esencialmente político de la práctica profesional se explica desde el momento en que ella cumple una función específica en la reproducción de las relaciones sociales, esto es, se inserta en el ámbito de las relaciones de poder de la sociedad capitalista. Por otro lado, vimos también que los condicionamientos objetivos del contexto histórico-social pueden ser re-significados en las respuestas del colectivo profesional, existiendo una autonomía relativa del trabajador social, que se funda y se torna posible a partir del carácter contradictorio de las relaciones sociales. De esta forma, el carácter político del TS también se hace presente en la tensión que existe entre el control y encuadramiento de las clases subalternas, y la lucha por los derechos de ciudadanía y el acceso a servicios/recursos fundamentales. La naturaleza contradictoria de nuestra profesión, que interviene en la vida cotidiana de grupos sociales subalternizados (en sus formas de expresión, resistencia y creación) develándola y descifrándola en sus contradicciones, es condición de posibilidad para que ella se afirme en una dirección social alternativa y anclada con las luchas sociales de su tiempo. Por ello, su privilegiada dimensión política se nutre de la potencial articulación entre los sectores populares y los programas institucionales en el campo de los servicios sociales, que su trabajo puede desarrollar (V.v.A.a., 1986: 61- 62) -siempre que mediado por una comprensión rigurosa y crítica de su ámbito de actuación.

Hay otra dimensión política más amplia pero que es fundamental para alimentar una postura crítica en la práctica de intervención cotidiana; es aquella susceptible de constituir la dirección social de un proyecto colectivo profesional que oriente y de sentido al TS en su tiempo histórico.

Al reconocer que los límites del trabajo profesional se ubican en las relaciones existentes entre el Estado y las clases sociales, podemos comprender cómo la expansión del espacio profesional está ligada al "ritmo" de las luchas sociales: politización de las necesidades sociales; conquistas sociales; explícitación de la "cuestión social"; entre otros. Esto es, depende también del fortalecimiento del movimiento democrático y popular.

La ampliación de la práctica profesional y el enfrentamiento del conservadurismo presente desde los orígenes del TS, que se dio en determinados momentos históricos (piénsese en el proceso de Renovación del Servicio Social Brasilero), requirió de una profundización en la producción de conocimientos y de una mayor calificación del trabajo profesional, pero también y fundamentalmente, de un contexto de conquistas de derechos cívicos y sociales. Es por esto que, si el TS pretende afirmar una orientación alternativa a su práctica profesional, superando su lastro y origen conser- 
vador, debe apuntar (con las necesarias mediaciones ético-políticas y teóricometodológicas) a la consolidación de un proyecto profesional que dé dirección y sentido a sus intervenciones; proyecto profesional necesariamente anclado a un proyecto de sociedad crítico de la explotación y de las múltiples expresiones de la opresión.

\section{El proyecto ético-político profesional y tentativas de construcción de un Trabajo Social crítico}

Habiendo, en la primera parte de este trabajo, caracterizado el significado y los fundamentos socio-históricos del TS, analizando diversas determinaciones de la práctica profesional que nos permiten reflexionar en torno de sus límites y posibilidades, nos centramos ahora, en algunos ejes de trabajo que nos posibiliten pensar en aquello que puede incidir críticamente en la configuración de una dirección social alternativa de la práctica profesional: el proyecto ético-político.

\section{1. ¿Qué significa el proyecto ético-político para el TS? Algunos ele- mentos para su historización}

Podríamos pensar, junto con Netto (en: Borgianni; Guerra; Montaño, 2003: 274) que un proyecto profesional representa la auto-imagen de una profesión y los valores que la legitiman socialmente; delimita sus objetivos y funciones; formula los requisitos (teóricos, institucionales y prácticos) para su ejercicio; prescribe normas para el comportamiento de los profesionales y establece las bases de la relación con los usuarios de sus servicios, con las otras profesiones, con las organizaciones e instituciones privadas y públicas. De esta manera y tal como fue resaltado anteriormente, los proyectos profesionales tienen ineliminables dimensiones políticas, tanto en un sentido amplio (relacionado con proyectos societarios), como en un sentido estricto (presente en las perspectivas particulares de la profesión).

¿Pero, por qué hablamos de dimensiones éticas y políticas?

La ética atraviesa a la profesión como un todo, que en sus varios elementos políticos, técnicos, prácticos y teóricos, se constituyen en esferas: esfera teórica donde se sintetizan las orientaciones filosóficas y teórico-metodológicas que sustentan las concepciones éticas de la profesión; esfera moral práctica referida al comportamiento individual y colectivo de los profesionales, los juicios de valor, las responsabilidades y el compromiso social, etc.; esfera normativa expresada en el Código de Ética que regula el ejercicio profesional. Por ello, la ética representa la posibilidad de la reflexión teórica sobre la moral orientada a lo humano-genérico (conexión con valores humanos emancipatorios), de la conciencia crítica sobre los valores que permean la práctica profesional. Al posibilitar la superación de la dimensión singular y el pragmatismo presente en las necesidades/demandas inmediatas que se le presentan al TS, esta puede permitir la crítica de la moral dominante (moralismo conservador y moralidad burguesa) y de los valores presentes en su intervención -tornando concientes las opciones y responsabilidades frente a la sociedad (Barroco en: Borgianni; Guerra; Montaño, 2003).

Sin embargo, si la conciencia y el conocimiento ético son necesarios para alcanzar una mayor autonomía en el ejercicio profesional, estos no son suficientes: 


\section{Katia I. Marro}

“La realización objetiva de ésta [la autonomía], supone la unidad entre ética y política, que se hace efectiva en el campo de los conflictos, de la oposición entre proyectos sociales, caracterizándose por la organización colectiva de la lucha entre ideas y proyectos que contienen valores y una dirección ética" ${ }^{14}$

Pensar a la praxis política como el medio adecuado para la realización práctica y efectiva de la ética profesiona ${ }^{15}$, la cual no es exclusiva de la profesión sino del conjunto de las fuerzas sociales progresistas, es la base de sustentación de un proyecto profesional que pretenda la realización y ampliación de derechos sociales, de la democracia, de una defensa intransigente de la ciudadanía; praxis anclada en un proyecto societario comprometido con la constitución histórica de individuos sociales libres (Barroco; lamamoto en: Borgianni; Guerra; Montaño, 2003: 244 y 267). De este modo, el proyecto profesional se configura como proyecto ético-político porque "una indicación ética sólo adquiere efectividad histórico-concreta cuando se combina con una dirección político-profesional" (Netto en: Borgianni; Guerra; Montaño, 2003: 280).

Por otro lado, remitirnos a su historización nos permite comprender que el llamado PEPP del TS no es una "invención académica arbitraria", mucho menos, una "moda" o receta que vendría a resolver los históricos dilemas de la profesión. Antes que eso, es una tentativa colectiva por construir un proyecto profesional comprometido e inspirado ética y políticamente en los valores emancipatorios que portan las luchas sociales de las clases subalternas: un proyecto colectivo capaz de incidir y dar una dirección social alternativa al mandato tradicional conservador del quehacer profesional.

Uno de los precedentes de esta tentativa contemporánea de consolidar una dirección social hegemónica crítica en la misma, fue el movimiento de Reconceptualización latino- americano, profundizándose ese intento de enfrentamiento y crítica del conservadurismo profesional, en el proceso de Renovación del TS, propio de algunos países de la región.

Mientras la crítica conservadora a la Reconceptualización caracterizó a este movimiento como un momento negativo para el TS ("retroceso"; "paralizante"; "que atentó contra la identidad profesional"; etc. ${ }^{16}$, tanto éste como el período que le procedió durante la década de 80 , fueron atravesados por innumerables esfuerzos colectivos -en el plano teórico y práctico- por criticar y superar el lastro conservador del TS. Fue, fundamentalmente, en el período posterior a la Reconceptualización donde se diseñan para el TS latinoamericano líneas de debate que, criticando las limitaciones de ese proceso (dualidad entre teoría y práctica, mecanicismo, escaso rigor en el manejo de la teoría, militantismo) y apropiándose de sus intentos críticos (enfrentamiento del conservadurismo, aproximación a la teoría social crítica marxista, ligación con el movimiento social), abren perspectivas teórico-metodológicas y marcos interpretativos de gran importancia para el TS, que determinarían las coordenadas del debate de las próximas décadas en la región.

\footnotetext{
${ }^{14}$ Barroco en: BORGIANNI, E.; GUERRA, Y.; MONTAÑO, C. Op.cit., p. 234.

${ }^{15}$ Inclusive porque existe una relación intrínseca entre valores y principios éticos, y las formas en que éstos se concretizan en prácticas morales y orientaciones políticas de los sujetos y clases sociales que asumen para sí alguno de los proyectos societarios en pugna (Retana en: Borgianni; Guerra; Montaño, 2003: 340).

${ }^{16}$ Una expresión contemporánea de esa crítica se encuentra en el libro organizado por Di Carlo (2004). Para una crítica a la crítica conservadora de la Reconceptualización. Cf. NETTO, J. P. «A crítica conservadora à Reconceptualização» en: Revista Serviço Social e Sociedade n 5. São Paulo: Cortez, 1981.
} 
Es importante destacar que ya se hacían presentes, aunque de forma germinal, en este momento del debate del TS latinoamericano, las siguientes preocupaciones: el significado del TS en la división socio-técnica del trabajo; el significado de los servicios sociales; preocupaciones con la identidad profesional; y aparecían temas tales como; renovación y conservadurismo; mesianismo y fatalismo; el problema de la hegemonía de un proyecto profesional vinculado a la clase trabajadora; entre otros (V.v.A.a., 1986).

Esta preocupación por la "[...] construcción de un proyecto profesional orientado para los intereses sociales de los trabajadores"17, o comprometido con "[...] un proyecto de clase alternativo y opuesto a aquel para el cual el asistente social fue convocado"18, tenía en el Centro Latinoamericano de Trabajo Social (CELATS) un componente fundamental: éste debía "[...] asumir el papel de centro dinamizador de la hegemonía del Servicio Social crítico en América Latina"19. De este modo, tanto la Asociación Latinoamericana de Escuelas de Trabajo Social (ALAETS) como el CELATS en su proyecto fundador, cumplieron en la época dos funciones esenciales: posibilitaron la articulación del TS latinoamericano y la formulación de un pensamiento crítico en el TS. De ahí, su participación en la organización y articulación de las investigaciones de vanguardia que buscaban dinamizar la elaboración teórica del TS latinoamericano.

Pero, ¿qué sucedió con este debate en los años posteriores?, ¿qué importancia mantuvo esta interlocución del TS latinoamericano?

A modo de hipótesis podríamos preguntarnos si durante las décadas posteriores, mientras el Servicio Social (SS) brasilero buscó apropiarse críticamente de este legado y consiguió profundizar algunos de los "caminos" abiertos por el debate latinoamericano -desarrollo de la pos-graduación pública, de la investigación y de un mercado editorial; interlocución madura con la teoría social crítica ${ }^{20}$; maduración intelectual y organizativa de la categoría ${ }^{21}$-, hasta que punto en el resto de la región no predominó, a grandes rasgos, una perspectiva modernizadora entrampada en preocupaciones profesionalistas y tecnicistas (gerencia social, gestión social, mediación) que, por descuidar una lectura crítica del significado histórico-social de la profesión, se tornó funcional (o impotente frente) a las medidas neoliberales que caracterizaron las reformas sociales de la región ${ }^{22}$

De ese modo, si el SS brasilero consolidó durante los años ‘90 un recorrido

\footnotetext{
${ }^{17}$ V.v.A.a. Serviço Social Crítico: problemas e perspectivas.Op. cit., p. 58. Traducción K. Marro.

${ }^{18}$ Op. cit., p. 60.

${ }^{19}$ Op. cit., p. 32

${ }^{20}$ E incorporación de matrices teórico-metodológicas compatibles con la ruptura del conservadurismo, capaces de realizar la crítica profunda de las relaciones sociales vigentes.

${ }^{21}$ En el SS brasilero podríamos destacar como ejes que articularon el debate de los años ' 80 , fundamentalmente, la cuestión teórico-metodológica (crítica al conservadurismo y al marxismo vulgar), y la historicidad del SS (en su relación con el Estado y el movimiento de las clases sociales), así como también el de la formación profesional. Ya en la década del ' 90 , otro de los temas que se ubicó en el centro de la reflexión profesional, fue el de los valores y de la ética profesional. (lamamoto en: Borgianni; Guerra; Montaño, 2003: 254).

${ }^{22}$ No desconsideramos que el desarrollo de dicha hipótesis supondría un arduo trabajo de investigación para el TS latinoamericano, que necesariamente debería analizar las determinaciones históricas del contexto social del periodo en cuestión para cada país. En ese sentido, los rumbos del SS brasilero no pueden comprenderse sin su ligación durante los años 80/90 al movimiento de las fuerzas sociales y populares progresistas, en la lucha por la democratización y conquista de la ciudadanía, materializada parcialmente en la Constitución del '88.
} 


\section{Katia I. Marro}

colectivo que se sintetiza en las Directrices Curriculares, en el Código de Ética ${ }^{23}$ y en la Ley de Reglamentación Profesional (procesos enmarcados en determinadas posibilidades socio-históricas), eso no torna al Proyecto ético-político profesional un "producto particular" o una "invención" de nacionalidad brasilera -argumentos que vienen sirviendo, claramente, para descalificar el debate. El proyecto éticopolítico profesional es la búsqueda múltiple y cotidiana por la construcción colectiva de una dirección social hegemónica que permita alimentar críticamente las prácticas profesionales en el sentido del enfrentamiento y superación del conservadurismo, y por ello, es legatario de los intentos latinoamericanos precedentes (la Reconceptualización y el proceso de Renovación que supuso en algunos países), y se inserta en un proyecto político societario más amplio.

La recuperación de la interlocución del TS latinoamericano en los días actuales, donde el SS brasilero tiene una enorme contribución a ofrecer, es una tentativa crítica que se nutre y se enmarca en un contexto histórico donde las reformas neoliberales vienen implicando una profunda regresión histórica en el trato a la "cuestión social", en la democracia y en la ciudadanía; y también, donde las luchas sociales y expresiones populares vienen buscando resurgir/renacer luego de tamaña devastación.

\section{2. ¿Cuál es su significación histórica en el momento contemporá- neo?}

Partimos de preguntarnos entonces, por el significado histórico del PEPP y percibimos que son varios los elementos que explican el resurgimiento de este desafío en el seno del TS latinoamericano. En el apartado anterior reconocimos que esta tentativa por construir un proyecto colectivo alternativo de profesión (resonando de múltiples maneras en el colectivo profesional de los diversos países de la región), que nutrido por su legado histórico, se resitúa en los días actuales, está indisociablemente ligado a un cierto resurgimiento de movimientos de protesta y al aumento de la conflictividad social en América Latina, como consecuencia de los procesos de represión, empobrecimiento, y de "devastación" económica, política y cultural que nuestras sociedades vienen sufriendo desde la ofensiva del capital de los años '70.

Por otro lado, se hace necesario también mencionar otros elementos de la realidad histórica que inciden directamente sobre el TS. El cuadro político y económico configurado en la última década expresó, a grandes rasgos, una transformación en la orientación y en la funcionalidad de las políticas sociales (Montaño en: Borgianni; Guerra; Montaño, 2003) derivada de un paulatino proceso de externalización de la "cuestión social" del orden económico político y de reorientación hacia la esfera privada (la familia, el individuo, el mercado), que implicó un retroceso a una visión individualista, psicologizante y moralizadora en el trato a la misma -embutida en las res-

\footnotetext{
${ }^{23}$ Código de Ética que explícita su vinculación a un proyecto societario emancipador -»sin dominación, explotación de clase, etnia o género»- ; su dimensión política al defender la equidad, la justicia social, la democracia, la ciudadanía y los derechos humanos; postula como valor central, la libertad del hombre; establece un compromiso con los derechos del usuario y la calidad de los servicios prestados; busca garantizar la autonomía y la criticidad profesional; afirma el compromiso con la formación profesional y con los órganos de la categoría. CFESS. Código de Ética do Assistente Social.
} 
puestas que el Estado viene ensayando ante el conflicto social (focalización, privatización, mercantilización, refilantropización). El estilo meritocrático de las políticas sociales se complementa, de esta manera, con la mistificada "cultura de la dependencia del Estado paternalista" (Potyara en: Borgianni; Guerra; Montaño, 2003: 80), que sirvió de fundamento para el desmonte y la precarización de derechos sociales conquistados otrora. Los efectos despolitizantes y fragmentadores de dichas respuestas sociales fueron reforzados, en este modelo, con sistemáticos intentos de criminalización de la "cuestión social" y penalización de los conflictos sociales.

De esta manera, debido a los profundos cambios en el mundo de la producción, el agravamiento de la pobreza y de las desigualdades sociales, la precarización de las respuestas sociales ante las mismas, etc., se evidencia una sustantiva transformación en las condiciones socio-históricas de la producción de la "cuestión social". Podemos decir que:

"[...] se presencia hoy una renovación de la vieja cuestión social, inscripta en la propia naturaleza de las relaciones sociales capitalistas, bajo otros ropajes y nuevas condiciones socio-históricas de su producción/reproducción en la sociedad contemporánea, profundizando sus contradicciones"24.

El cuadro de situación caracterizado implica profundas transformaciones para el TS y apunta una serie de desafíos que se imponen para el ejercicio profesional. Desde la precarización de las condiciones socio-laborales y de los recursos materiales disponibles, hasta la crisis de legitimidad que estas transformaciones suponen para el TS (básicamente por la reducción y precarización de la respuesta estatal), se configura un campo de límites/ posibilidades para la profesión que es necesario enfrentar con nuevas funciones y competencias ${ }^{25}$, en los marcos de una propuesta crítica colectiva que le de dirección social a dichas intervenciones en el sentido de viabilizar el acceso a derechos sociales y el ejercicio de la ciudadanía (Iamamoto, 2003: 78).

En este marco, destacamos la importancia de la apuesta en la construcción de un PEPP alimentado de una fructífera articulación del TS latinoamericano, que nos permita incidir en la realidad social de nuestros países a partir de una práctica profesional comprometida en su cotidiano con la defensa de derechos sociales y de la democratización de la vida social (de la política y de las fuerzas productivas), y que tenga por horizonte -en sintonía con las fuerzas sociales progresistas- la creación de una nueva hegemonía en el cuadro de las relaciones sociales. Un proyecto profesional que, articulando la dimensión ética y la dimensión política del ejercicio profesional (fundado en principios y valores como libertad, ciudadanía, justicia social, políticas sociales universales, ampliación de la esfera pública y de la participación popular, eliminación de la explotación y dominación) dispute en el colectivo una dirección social para el TS que lo sitúe en la perspectiva de los intereses de sus usuarios, inspirada en un proyecto societario de emancipación social.

Necesitamos para ello, apostar en la organización política y corporativa de la categoría profesional; trabajar en la conformación de un marco legal profesional que

24 IAMAMOTO, M. «Aquestão social no capitalismo». Op. Cit., pp. 67-68. Traducción K. Marro. ${ }^{25}$ Afinadas tanto con las necesidades sociales de las clases subalternas, como con las nuevas dimensiones y demandas presentes en el mercado de trabajo. 
exprese los valores y acuerdos colectivos; avanzar y materializar estas luchas en el ámbito de la formación profesional (planes de estudio, cursos de postgrado, prácticas pre-profesionales) y vincular estos esfuerzos con las experiencias organizativas $y$ movimientos populares que expresan en sus luchas los principios éticos y políticos que nortean el proyecto profesional (Montaño en: Borgianni; Guerra; Montaño, 2003: 29-30), orientados, fundamentalmente, para que este esfuerzo de ampliación de los límites de la ciudadanía burguesa se haga presente en la práctica de intervención cotidiana de los trabajadores sociales, en sus diversos espacios de trabajo. Este es el gran desafío de nuestros días actuales.

El desafío principal del PEPP es el de concretizar en la vida práctica una nueva ética en la profesión (objetivos práctico-estratégicos alimentados de valores emancipatorios), articulada a la lucha por la construcción de una nueva hegemonía en la sociedad. EI TS necesita traducir sus compromisos éticos en propuestas colectivas y acciones académicas/ políticas dirigidas al conocimiento y enfrentamiento de la "cuestión social" tal como ella se configura en la actualidad (lamamoto en: Borgianni; Guerra; Montaño, 2003: 267), y de esta manera, poder incidir en la cotidianeidad de la práctica profesional.

Si nos referimos ahora, de forma general y sin intenciones de abordar el tema en su profundidad, a los intentos existentes en el TS latinoamericano en los días actuales, no podemos dejar de mencionar el trabajo que viene desarrollando, de forma germinal en esta dirección, el Comité Mercosur de Organizaciones Profesionales existente desde el año $1996^{26}$. Articulado a innumerables esfuerzos que vienen desenvolviéndose en los distintos espacios del colectivo profesional de los diversos países que lo integran, el Comité elaboró y aprobó los Principios Éticos y Políticos básicos para el SS del Mercosur en el año 2000. Los mismos pretenden orientar, en términos generales, el ejercicio de la profesión en los distintos países, asumiendo, entre otras cuestiones: la defensa/ampliación de la democracia y de los derechos humanos; la búsqueda por la garantía de formas de acceso real de todas las personas a los bienes materiales y culturales producidos socialmente; la defensa y reivindicación por políticas sociales universales y por la inalienable responsabilidad estatal ante la cuestión social; el respeto a la autodeterminación de personas y movimientos populares; el compromiso con la formación profesional permanente, con la construcción de marcos legales y con la garantía de condiciones dignas de trabajo y ejercicio de la profesión.

En este sentido, rescatamos la importancia de esta instancia de articulación concreta del TS latinoamericano que viene buscando dar respuestas ante los desafíos planteados a nuestra profesión (en materia de intervención profesional, de reglamentación y de formación académica) y pronunciándose frente a medidas económico-políticas regresivas (como por ejemplo, el ALCA) y a situaciones de autoritarismo y represión en la región, que van a contramano de los acuerdos éticos y políticos que se vienen ensayando.

A su vez, la propia refundación de ALAETS es un debate que también está en el orden del día, en función de que este organismo pueda permitir la articulación de

${ }^{26}$ Esta instancia de articulación de organizaciones representativas de la profesión de distintos países de América Latina, se propone la construcción de pautas generales para el TS, entendidas como posicionamientos políticos y sociales para enfrentar las desigualdades sociales de la región. Aglutina actualmente a organizaciones profesionales de Brasil, Argentina, Paraguay y Uruguay (García en: Borgianni; Guerra; Montaño, 2003) 


\section{$\mathrm{A}\lrcorner コ\lrcorner$ 月А}

proyectos ético-políticos críticos en la región, que confronten con las perspectivas tecnócratas presentes en el TS (Rozas, 2004: 48).

\subsection{Servicio Social y luchas sociales. A modo de conclusión}

El retroceso histórico evidenciado en la realidad anteriormente enunciada, resitúa con más fuerza el desafío para el Trabajo Social de la defensa intransigente de derechos sociales de ciudadanía, defensa que necesita anclarse a las luchas y experiencias organizativas societarias, porque son las prácticas socio-políticas de dichos movimientos las que vienen evidenciando los límites de la intervención regresiva del Estado ante la "cuestión social".

En esa necesaria articulación con los movimientos sociales y de clases, el Trabajo Social necesita estar atento a las consecuencias sociales regresivas que puedan implicar, tanto un rechazo del Estado como actor esencial en la garantía de derechos de ciudadanía, como un "tercer sector" que se pretenda sustituto del Estado en sus obligaciones fundamentales. Sin por ello negar, las propias tensiones que atraviesan y caracterizan a la ciudadanía, esto es, su universalidad "limitada", los límites de su "encapsulamiento" nacional, su contrapeso de "tutelaje" y pasividad, etc.

No obstante, la complejidad de dichos dilemas/desafíos es mucho más profunda de lo que parece en el papel. Por un lado, porque trabajamos con sectores de clases que históricamente han experimentado o la "cara" clientelar del Estado, o la "cara" represiva; sectores subalternos que, cuando consiguen politizar sus necesidades sociales, en muchos casos, crean una actitud de rechazo hacia las formas políticas institucionales (igualando Estado a gobierno), las cuales padecen "en carne propia" como "dependencia". Por otro lado, porque la heterogeneidad político-ideológica que atraviesa a las organizaciones de la sociedad civil - inclusive por la propia historia de nuestros países - y el regresivo escenario político y social donde actúan, nos dificulta separar hasta donde ellas son una forma de resistir al desmonte neoliberal, y hasta donde son su complemento funcional (Montaño en: Borgianni; Guerra; Montaño, 2003).

Finalmente, consideramos que la lucha por derechos sociales y una ciudadanía que no implique "dependencia" y "pasividad", lucha que reconozca la importancia de imprimir esas conquistas en la propia materialidad institucional del Estado, lucha que contiene pero transciende los márgenes del Trabajo Social, constituyen elementos esenciales de los problemas contemporáneos que nos desafían. La lucha por derechos sociales y políticas sociales universales se ubica así, en un proceso mayor de defensa de una esfera pública democrática, producto y potencia de aquellas conquistas. Pero, ¿de qué esfera pública estamos hablando? Consideramos que los movimientos y organizaciones sociales, los partidos políticos, los sindicatos, las organizaciones comunitarias, constituyen todas ellas espacios de construcción de la esfera pública, la cual no está ni disociada ni se contrapone al Estado, siendo un momento del mismo. Esfera pública que es expresión de las relaciones de disputa y poder presentes en la sociedad civil, y tiene incidencias directas en el propio Estado, arena privilegiada de la lucha de clases.

La lucha por la ampliación y radicalización de la esfera pública democrática, anclada a las luchas sociales y experiencias de resistencia contemporáneas, se com- 


\section{Katia I. Marro}

plementa con la necesidad de resistir ante tendencias privatizantes o de desresponsabilización estatal -sea con relación a la mercantilización de los servicios sociales, sea respecto a organizaciones filantrópicas-, que representen un patrón regresivo de intervención ante la "cuestión social". Por ello, sólo a partir de un horizonte de universalización y derechos sociales es que podemos pensar en formas más democráticas y dignas de dar respuesta a las desigualdades sociales y a las múltiples necesidades "urgentes" de la vida social.

Ubicar entonces, los límites del ejercicio profesional en la relación que se establece entre el Estado y las clases sociales, nos permite entender que la posibilidad de expansión del espacio profesional está estrechamente ligada a las conquistas y luchas sociales, además de tener como condición una rigurosa formación teóricometodológica que sitúe al TS a la altura de los desafíos contemporáneos. De aquí deriva también la importancia de la consolidación de un PEPP que, solidario con las fuerzas progresistas sociales, enfrente el neoliberalismo a través de las prácticas cotidianas de intervención profesionales.

La consolidación de la hegemonía de un proyecto colectivo que busque desterrar el conservadurismo del TS, solidarizándose con los proyectos societarios de las clases subalternas, no supone la negación de las diferencias en el colectivo profesional, mucho menos, la aceptación pasiva de esta dirección social. Esta búsqueda por imprimir una dirección social alternativa en el ejercicio profesional reconoce la disputa teórico-académica y político-ideológica en el seno profesional, como una instancia fundamental en la consolidación de dicha hegemonía que articule y sintetice las diversidades del colectivo.

La lucha por la hegemonía del PEPP representa la búsqueda por el consenso activo y organizado del colectivo profesional en torno de valores socio-céntricos; lucha donde la hegemonía se articule con el pluralismo ${ }^{27}$, porque ella representa la potenciación/síntesis de las diferencias en aquello que las une: una dirección social estratégica que de sentido al quehacer profesional del TS, solidaria con la superación de la explotación y la dominación. Si entendemos al colectivo profesional como un campo de tensiones y disputa, podemos comprender que la construcción de un PEPP que luche para tornarse hegemónico en el TS, es fundamental para imprimir en la práctica profesional una dirección social alternativa al conservadurismo, presente desde su génesis. Sabemos que este descubrimiento - el de la ligación explícita que existe entre los proyectos societarios y nuestra profesión - es un patrimonio que se remonta, aunque de forma germinal, al propio movimiento de Reconceptualización. Re-situemos, entonces, este desafío en las condiciones históricas contemporáneas.

\footnotetext{
${ }^{27}$ Es importante resaltar que el concepto de hegemonía tal como es entendido aquí (referenciado en Gramsci) no supone consentimiento pasivo, ni monopolio del poder, mucho menos, implica despolitización. Por ello, pluralismo y hegemonía se auto-implican porque aquel no cobra un sentido liberal sino que supone la unidad de la diversidad. Pluralismo en el plano del pensamiento no es sinónimo de eclecticismo o relativismo; es sinónimo de apertura y respeto por la posición ajena, considerándola como necesaria al desarrollo de la propia posición y de la ciencia, no porque todas ellas serían igualmente válidas, sino porque el debate es fundamental para el descubrimiento de verdades científicas, verdades que sólo pueden tener como referencia ontológica la objetividad de lo real (Coutinho, 1995).
} 


\section{Bibliografía}

BORGIANNI, E.; GUERRA, Y.; MONTAÑO, C. Servicio Social Crítico. Hacia la construcción del nuevo proyecto ético-político profesional. São Paulo, Cortez, 2003.

CFESS. Código de Ética do Assistente Social. Lei 8662/93, 3o edição, Brasília, 1997.

COUTINHO, C. N. "Pluralismo: dimensões teóricas e políticas" en: Cadernos Abess $n^{\circ} 4$, Ensino em Serviço Social: pluralismo e formação profissional. São Paulo, Cortez, 1995.

DI CARLO, E. (Org.) La profesión de Trabajo Social. Naturaleza, significado socialy formas de acción profesional .Tomo 1. Mar del Plata, UndMP, 2004.

IAMAMOTO, M. "A questão social no capitalismo" en: Revista Praia Vermelha nº 8. Rio de Janeiro, UFRJ/PPGESS, 2003.

. "Serviço Social brasileiro e a articulação latino-americana" en: Revista Temporalis $\mathrm{n}^{\circ} 7$, Articulação Latino-Americana e Formação Profissional. Porto Alegre, Abepss, 2004.

. Servicio Social y división del trabajo. Un análisis crítico de sus fundamentos. São Paulo, Cortez, 1997.

MONTAÑO, C. La naturaleza del Servicio Social: un ensayo sobre su génesis, su especificidad y su reproducción. São Paulo, Cortez, 2000.

NETTO, J. P. "A crítica conservadora à Reconceptualização" en: Revista Serviço Social e Sociedade n 5 . São Paulo: Cortez, 1981.

. Capitalismo monopolista y Servicio Social. São Paulo, Cortez, 1997.

ROZAS, M. "Historia de las organizaciones político-académicas en América Latina" en: Re vista Temporalis n ${ }^{\circ}$ 7. Articulação Latino-Americana e Formação Profissional. Porto Alegre, Abepss, 2004.

V.v.A.a. Serviço Social Crítico: problemas e perspectivas. São Paulo, Cortez, 1986. 